\section{Actions of propofol on pontine neurons controlling arterial pressure in rats}

Andrei V. Krassioukov MD PhD, ${ }^{*} \dagger$

Adrian W. Gelb MB ChB, ${ }^{*} \ddagger$ Lynne C. Weaver DVM PhD* $†$
Tonic firing of pontine neurons provides excitatory input to the vasomotor centre in the ventrolateral medulla. To increase our understanding of the actions of propofol on CNS neurons controlling the cardiovascular system, we evaluated the effects of propofol on this tonic firing of pontine neurons. The actions of propofol (doses 1-4, respectively; $24 \pm 2,40 \pm 4,65 \pm$ 3 and $104 \pm 3 \mathrm{mg} \cdot \mathrm{kg}^{-1} \cdot \mathrm{hr}^{-1}$ ) on the pontine neurons were studied using eight atropinized Wistar rats. Electrical activity of renal sympathetic nerves, systemic arterial blood pressure and heart rate were recorded. Propofol decreased renal nerve activity by $3 \pm 2 \%, 23 \pm 3 \%, 33 \pm 3 \%$ and $52 \pm 4 \%$ at the four doses. Arterial pressure and heart rate decreased similarly in a dose-dependent manner. Sympathetic and cardiovascular responses to blocking neurons in the pontine reticular formation by microinjection of glycine were depressed by propofol. Renal nerve activity was decreased by $44 \pm 5 \%, 41 \pm$ $4 \%, 28 \pm 3 \%$ and $13 \pm 2 \%$ afier pontine blockade during infusion of doses 1 to 4, respectively. Similarly, arterial pressure was decreased by $25 \pm 3,15 \pm 2,12 \pm 1$ and $5 \pm 2 \mathrm{mmHg}$. Finally, heart rate decreased by $27 \pm 6,20 \pm 4,18 \pm 4$ and $13 \pm 5$ beats per min as the propofol dose increased. The tonic firing of pontine neurons was minimally depressed by the lower two doses of propofol but higher doses did appear to depress their firing, demonstrating dose-dependence of actions of this

\section{Key words}

ANAESTHETICS, INTRAVENOUS: propofol;

PONS;

SYMPATHETIC NERVOUS SYSTEM.

From the Department of Stroke and Aging, The John P. Robarts Research Institute*, Department of Physiology† and Department of Anaesthesiat, The University of Western Ontario.

Address correspondence to: Dr. Andrei Krassioukov, The John P. Robarts Research Institute, 100 Perth Drive, P.O. Box 5015, London, Ontario N6A 5K8.

Supported by the Heart and Stroke Foundation of Ontario and the Medical Research Council of Canada/Canadian Hypertension Society.

Accepted for publication 15th October, 1994. anaesthetic. In conclusion, at light levels of propofol anaesthesia, the hypotensive effects probably relate mostly to direct actions on the heart and peripheral vasculature because central sympathetic control of the circulation is not markedly disrupted. As the depth of anaesthesia is increased, selective effects on CNS vasomotor neurons become more apparent leading to depression of excitatory pontine inputs to the vasomotor neurons in the medulla.

La décharge tonique des neurones de la protubérance produit l'excitation du centre vasomoteur situé dans la partie ventrolatérale du bulbe. Nous avons évalué les effets du propofol sur la décharge tonique des neurones protubérantiels dans le but de mieux comprendre l'action du propofol sur le contrôle neural du système cardiovasculaire. L'action du propofol (aux doses suivantes de 1 à 4: $24 \pm 2 ; 40 \pm 4 ; 65 \pm 3$ et $104 \pm 3$ $m g \cdot \mathrm{kg}^{-I} \cdot \mathrm{hr}^{-1}$ ) sur les neurones protubérantiels a été étudiée sur huit rats Wistar atropinisés. L'activité électrique du sympathique rénal, la pression artérielle systémique et la fréquence cardiaque ont été enregistrées. Le propofol diminue l'activité nerveuse rénale aux quatre doses par $3 \pm 2 \%, 23 \pm 3 \%, 33$ $\pm 3 \%$ et $52 \pm 4 \%$. La pression artérielle et la fréquence cardiaque diminuent proportionnellement à la dose. Les réponses sympathiques et cardiovasculaires consécutives à l'inhibition de la formation réticulée de la protubérance par des microinjections de glycine sont déprimées par le propofol. Après linhibition protubérantielle, l'activité nerveuse rénale est diminuée de $44 \pm 5 \%, 41 \pm 4 \%, 28 \pm 3 \%$ et $13 \pm 2 \%$ respectivement pendant la perfusion des doses 1 à 4. Parallèlement, la pression artérielle diminue de $25 \pm 3,15 \pm 2,12 \pm 1$ et $5 \pm 2 \mathrm{~mm} \mathrm{Hg}$. Finalement la fréquence cardiaque diminue de $27 \pm 6,20 \pm$ 4, $18 \pm 4$ et $13 \pm 5$ b.p.m., parallèlement à l'augmentation de la dose. La décharge tonique des neurones protubérantiels n'est que très peu déprimée par les deux doses les plus faibles mais les doses plus importantes semblent la déprimer, démontrant ainsi la relation de dose à effet de cet anesthésique. Pour conclure, aux niveaux superficiels de l'anesthésie au propofol, lactivité hypotensive de cet anesthésique est vraisemblablement due à son action directe sur le coeur et le système vasculaire périphérique puisque le contrôle sympathique central de la circulation n'est pas perturbé profondément. A mesure qu'on approfondit l'anesthésie, les effets sélectifs du propofol sur les neu- 
rones vasomoteurs du SNC deviennent plus apparents, ce qui conduit éventuellement à la dépression de l'excitation neurale d'origine protubérantielle des neurones vasomoteurs $d u$ bulbe.

Clinical and laboratory studies of the hypotension and bradycardia that occur with infusions of propofol $(2,6-$ diisopropylphenol) have demonstrated that the depression of cardiovascular function is caused by direct actions on the heart and vessels as well as actions on the autonomic nervous system. ${ }^{1-10}$ However, the studies of mechanisms of actions of propofol on CNS neurons involved in vasomotor regulation are limited to a recent investigation in our laboratory. ${ }^{7}$ A fuller understanding of the mechanisms underlying cardiovascular changes induced by this anaesthesia may allow such changes to be prevented or more appropriate therapies to be developed to counteract them.

The rostral ventrolateral medulla and pontine reticular formation are important areas of the brain stem that control resting arterial pressure and heart rate through the sympathetic nervous system. ${ }^{11-13}$ Cardiovascular and sympathetic responses elicited in rats by microinjections of the inhibitory amino acid glycine into the rostral part of the ventrolateral medulla are similar under different anaesthetic agents including pentobarbitone, alfaxalonealfadolone, propofol and urethane., ${ }^{72-14}$ However, responses elicited by inhibitory amino acid blockade of pontine neurons are blunted by pentobarbital and urethane but can be evoked well under alfaxalone-alfadolone anaesthesia. ${ }^{12}$ The effect of propofol on pontine neurons has not previously been investigated.

Effects of anaesthesia on the pontine neurons merit exploration because recent studies have demonstrated that these neurons can provide powerful tonic excitatory sympathetic drive to support arterial pressure, ${ }^{12,13,15}$ in addition to their well-known role in controlling respiration. ${ }^{16}$ Neurons in the pons also provide excitatory input to the vasomotor neurons in the ventrolateral medulla. ${ }^{13,15}$ Thus, to increase our understanding of the actions of propofol on CNS neurons involved in cardiovascular control, we investigated the effects of propofol on the vasomotor neurons in the pons. Data from metabolic studies suggest that higher brain regions are more susceptible to depression by intravenous anaesthetics including propofol. ${ }^{2}$ The aim of this study was to evaluate the depression of tonic firing of pontine neurons by different doses of propofol. Therefore we investigated the sympathetic and cardiovascular responses to microinjection of the inhibitory amino acid glycine into the pons. ${ }^{12,13} \mathrm{~A}$ depressant action of the anaesthetic on these pontine neurons would lead to smaller responses to the amino acid blockade. Also, we compared the effects of propofol on pontine neurons in the present study with effects on ventrolateral medullary neurons observed in our previous study. ?

\section{Methods}

\section{Surgical preparation of animals}

After approval by the University of Western Ontario Animal Care Committee, experiments were performed on eight male Wistar rats weighing 200-400 g. Anaesthesia was induced with pentobarbitone sodium (MTC Pharmaceuticals, Canada, $40 \mathrm{mg} \cdot \mathrm{kg}^{-1}$, ip). The femoral artery was cannulated to monitor arterial blood pressure and to obtain samples for blood gas analysis (blood gas analyser, model 170, Corning Medical, USA). Arterial $\mathrm{pH}, \mathrm{PaO}_{2}$ and $\mathrm{PaCO}_{2}$ were kept in the normal range (pH: 7.35-7.45; $\mathrm{PaO}_{2}>100 \mathrm{mmHg} ; \mathrm{PaCO}_{2}: 25-40 \mathrm{mmHg}$ ). Metabolic acidosis was corrected by occasional small bolus injections of sodium bicarbonate and abnormalities due to hypo- or hyperventilation were corrected by adjusting respiratory rate and volume as required. Both jugular veins were cannulated; one was used for the infusion of propofol while the other was used for the continuous infusion of physiological saline $\left(0.01 \mathrm{ml} \cdot \mathrm{min}^{-1}\right)$ and for the administration of drugs. As the anaesthetic effects of pentobarbital diminished, propofol infusion was begun at the dose needed to maintain surgical anaesthesia (dose 2 , described below). Body temperature was monitored rectally and maintained at $37^{\circ} \mathrm{C}$ with a heating pad.

The tracheostomy tube was inserted and interfaced with a rodent ventilator (Harvard Instruments, USA) using minimal dead space in the associated tubing. The rats were paralysed with gallamine triethiodide (20 $\mathrm{mg} \cdot \mathrm{kg}^{-1}$ initially, followed by doses of $10 \mathrm{mg} \cdot \mathrm{kg}^{-1}$ as needed) and mechanically ventilated. Before each supplemental dose of gallamine was given, the depth of anaesthesia was assessed by examination of palpebral and withdrawal reflexes. Parasympathetic blockade (atropine, $1 \mathrm{mg} \cdot \mathrm{kg}^{-1} \dot{i}$, every two hours, Sigma Chemical Company, USA) was done to permit the effects of propofol on cardiac sympathetic tone to be assessed. This vagal blockade also obscured any possible vagolytic effects of gallamine on the heart. ${ }^{17}$

The rats were placed in a stereotaxic frame (David Kopf Instruments, USA) and sections of the interparietal and parietal bone were removed to expose the cerebellum and cortex overlying the brainstem. The brain surface was kept moist with saline-soaked gauze until immediately before microinjection. In all rats, the left kidney was exposed by a flank incision and the renal nerve was dissected from the renal artery at the hilus of the kidney. Approximately $2 \mathrm{~mm}$ was freed from the artery and the nerve was severed. The central end of the nerve was 
placed on a stainless steel bipolar electrode for recording tonic multifibre electrical activity. To isolate the nerves and electrodes from surrounding tissue and to prevent dehydration of the exposed nerves, the nerves and electrodes tips were covered with dental impression medium (Perfourm, Cutter Dental, USA). In each rat a pneumothorax was made to prevent movement artifacts in the neural recordings. Details of the experimental protocol have been described previously. ${ }^{12,18}$

Neural discharge was amplified (Grass P51I amplifier; Grass Instrument Co., USA) at a bandwidth of $30 \mathrm{~Hz}-3$ $\mathrm{kHz}$. After amplification, the signals were monitored on an oscilloscope and recorded on magnetic tape. Arterial pressure was measured (Statham Instruments, Inc., USA) and heart rate was determined using a Grass tachograph triggered by the systolic phase of each arterial pressure pulse. Heart rate and arterial pressure were displayed continuously on a Grass polygraph and recorded on magnetic tape.

\section{Experimental protocols}

Investigation of the effects of the intravenous infusion of four different doses of propofol (Zeneca Pharma, Canada) was begun four hours after induction of anaesthesia with pentobarbital. At this time surgical preparations were complete and the anaesthetic effects of pentobarbital had dissipated. In previous experiments in our laboratory, rats were fully conscious four hours after anaesthesia with $40 \mathrm{mg} \cdot \mathrm{kg}^{-1}$ pentobarbital. ${ }^{19}$ Propofol was infused at 24 $\pm 2 \mathrm{mg} \cdot \mathrm{kg}^{-1} \cdot \mathrm{hr}^{-1}$ (dose 1), $40 \pm 4 \mathrm{mg} \cdot \mathrm{kg}^{-1} \cdot \mathrm{hr}^{-1}$ (dose 2), $65 \pm 3 \mathrm{mg} \cdot \mathrm{kg}^{-1} \cdot \mathrm{hr}^{-1}$ (dose 3) and $104 \pm$ $3 \mathrm{mg} \cdot \mathrm{kg}^{-1} \cdot \mathrm{hr}^{-1}$ (dose 4). The doses of propofol were those used in our previous study and in other experimental studies in rats. ${ }^{6-8}$ Although much higher than doses used in humans, these doses are clinically comparable. The difference appears to relate to the rapid metabolic clearance of propofol by the liver in rats. ${ }^{20}$ The effects of all doses of propofol on resting sympathetic discharge, arterial pressure and heart rate were investigated in each animal $40 \mathrm{~min}$ after beginning the infusion. The dose of propofol was selected arbitrarily by the investigator in random order. To permit recovery from the higher doses of propofol, the infusion was returned to dose 1 .

After one hour of infusion of each dose of propofol, small volumes $(63 \pm 2 \mathrm{nl})$ of $1.0 \mathrm{M}$ glycine were injected unilaterally (21 injections) into the pons through glass micropipettes (tip size: $25 \mu \mathrm{m}$ ) using a picospritzer pressure injection system. Injections were made alternately on either side of the pons. These pipettes were positioned in the pons using stereotaxic methods according to the atlas of Paxinos and Watson. ${ }^{21}$ A diagram of the brain stem and spinal cord showing the localisation of the pon-

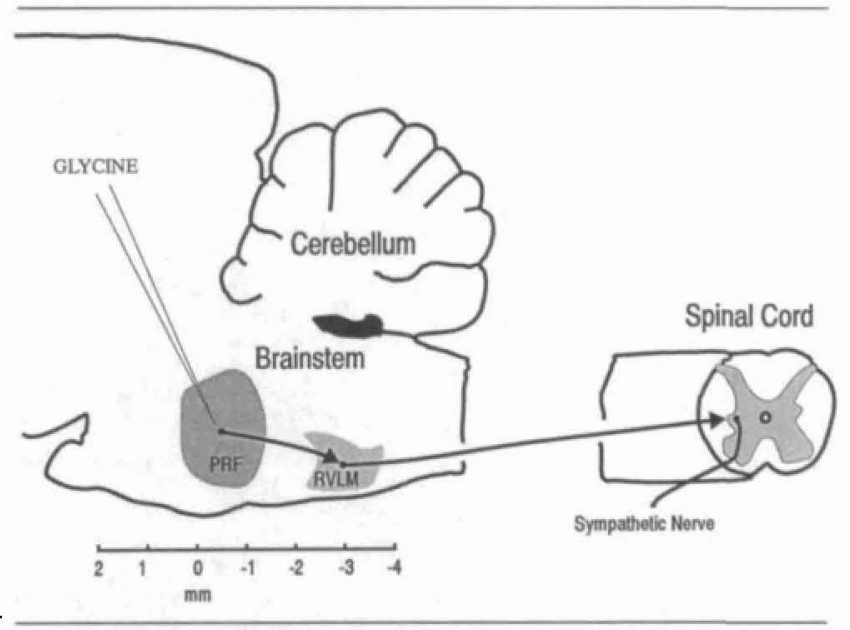

FIGURE I Diagram of the brain stem and spinal cord illustrating regions of microinjections of glycine into the pons and localisation of the vasomotor area within the rostral ventrolateral medulla (RVLM). Schematic pathways between the brain stem regions and their connections with spinal sympathetic preganglionic neurons (investigated in our laboratory previously ${ }^{13,15}$ ) are also shown on the diagram.

tine reticular formation and vasomotor area within the rostral ventrolateral medulla is presented on Figure 1. Ejection pressure and pulse duration were controlled by a picospritzer (General Valve Corporation, USA). Injection volumes were determined by the displacement of the meniscus in the pipette, observed through a microscope containing an ocular micrometer. The volume injected in any individual rat was constant but small differences between rats were unavoidable. Techniques of microinjection and stereotaxic positioning of the pipettes have been described in our previous publications. ${ }^{13,14,18}$

Arterial pressure, heart rate and renal nerve responses to glycine injections were monitored. The arterial pressure, heart rate and renal nerve responses to glycine microinjections into the pons were tested after $60 \mathrm{~min}$ of infusion of each dose of propofol. The effects of doses 1,3 and 4 of propofol on pontine responses were obtained in five of eight rats and the effects of dose 2 were obtained in six of the eight rats. Because our previous investigation ${ }^{7}$ showed that the effects of these infusions had reached a plateau or reached a point of minimal further change by $35 \mathrm{~min}$ of infusion, we assumed that a steady state had been achieved by $60 \mathrm{~min}$. Our previous studies also demonstrated that control injections of $1.0 \mathrm{M} \mathrm{NaCl}$ or $2.0 \mathrm{M}$ sucrose into the pontine reticular formation caused no neural or cardiovascular responses. ${ }^{12}$

All solutions of glycine contained a few drops of India ink to mark the injection sites. After the experiments, the rat brains were removed for histological verification of the sites of microinjections into the pons. Injection 
sites were plotted on stylized drawings ${ }^{21}$ of transverse sections of the rat pons.

\section{Analysis of data}

Sympathetic discharge was quantified by cumulative integration of the voltage recorded. Electronic noise in the signal was determined at the end of the experiment by obtaining a sample of signal after the animal had been given an overdose of anaesthetic. The voltage in this sample of the noise was integrated and subtracted from the total integrated signal to obtain an estimate of sympathetic activity in $\mu \mathrm{V} \cdot \mathrm{sec}$. The voltage was full wave rectified and integrated in ten-second intervals using a programme prepared by R.C. Electronics Inc. (USA). Control periods consisted of four to six ten-second samples.

To determine statistical changes in neural activity, arterial pressure and heart rate, a one-way analysis of variance (ANOVA) with repeated measures was used to compare responses in (1) renal nerve activity, (2) arterial pressure and (3) heart rate to microinjection of glycine into the pons during infusion of the different doses of propofol. ${ }^{22}$ Comparisons between percentage changes in nerve activity were made after square root normalization of percentage values. Tukey's test was used for comparisons of mean values. ${ }^{22}$ Differences were considered significant when $P<0.05$, and variability was expressed as a standard error of the mean.

\section{Results}

Decreases in sympathetic nerve activity, arterial pressure and heart rate occurred during the continuous infusion of different doses of propofol (Figures 2 and 3). Renal nerve activity and arterial pressure were progressively depressed with increasing doses of propofol and the rhythmic firing pattern was lost (Figure 2). These anaesthetic effects on basal renal sympathetic nerve firing and cardiovascular variables (Figure 3 ) followed a pattern similar to those observed in our previous investigation.

\section{The responses to the microinjection of glycine into the pons}

Figure 4 illustrates typical responses to microinjection of glycine into the pontine reticular formation in a rat. Unilateral microinjection of glycine into the pons at dose $2\left(40 \mathrm{mg} \cdot \mathrm{kg}^{-1} \cdot \mathrm{hr}^{-1}\right)$ caused a brisk decrease in arterial pressure, heart rate and renal nerve activity. These responses started within five to ten seconds after the injection, reached a maximum at 20-40 sec, and all variables returned to control within $120 \mathrm{sec}$. Mean arterial pressure decreased by $25 \mathrm{mmHg}$, renal nerve activity decreased by $42 \%$ and heart rate decreased by $20 \mathrm{bpm}$ in this rat.

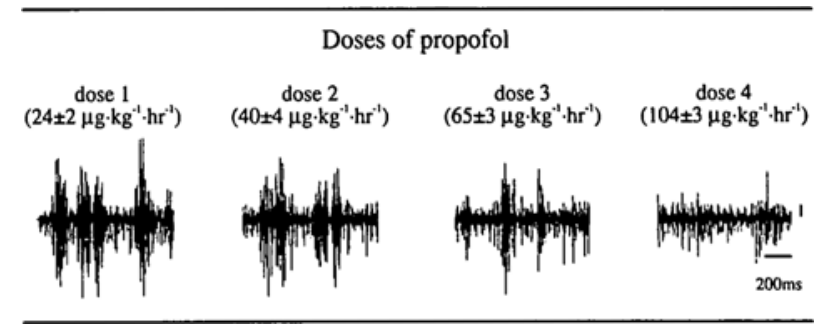

FIGURE 2 Renal nerve activity (original neurograms) sampled 35 $\min$ after beginning the infusion of four different doses of propofol in a rat. See Methods for details of doses 1-4. Vertical calibration: $50 \mu \mathrm{V}$.

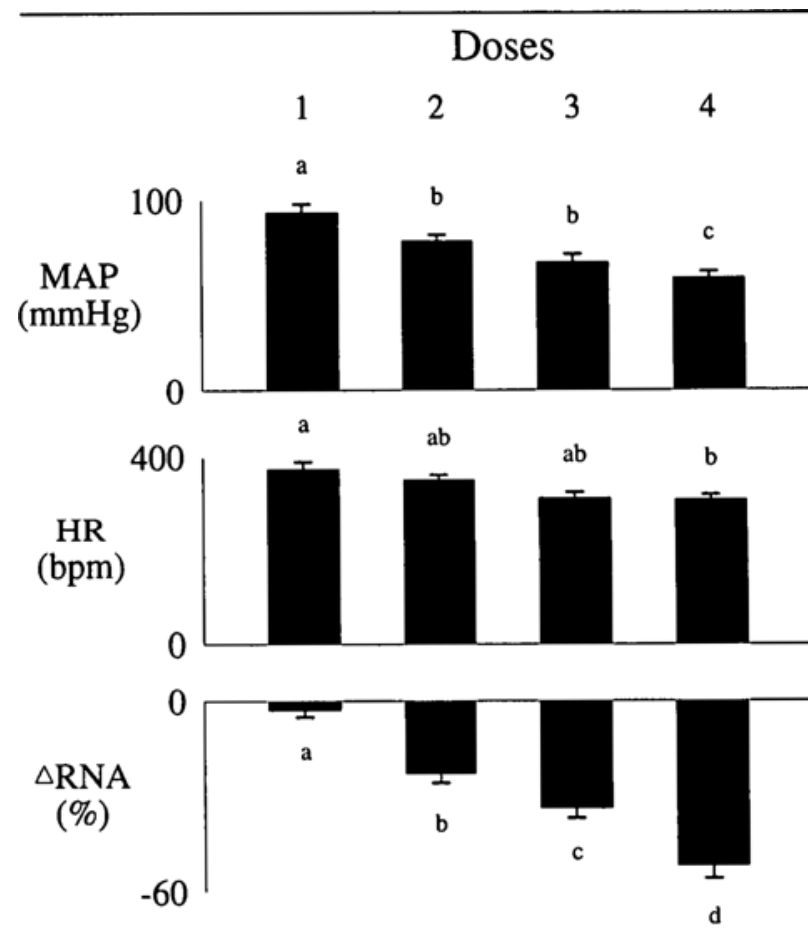

$\begin{array}{ll}\text { dose 1: } 24 \pm 2 \mu \mathrm{g} \cdot \mathrm{kg}^{-1} \cdot \mathrm{hr}^{-1} & \text { dose 2: } 40 \pm 4 \mu \mathrm{g} \cdot \mathrm{kg}^{-1} \cdot \mathrm{hr}^{-1} \\ \text { dose 3: } 65 \pm 3 \mu \mathrm{g} \cdot \mathrm{kg}^{-1} \cdot \mathrm{hr}^{-1} & \text { dose 4: } 104 \pm 3 \mu \mathrm{g} \cdot \mathrm{kg}^{-1} \cdot \mathrm{hr}^{-1}\end{array}$

FIGURE 3 Levels of the mean arterial pressure (MAP), heart rate (HR) and percent depression of renal nerve activity (RNA) after 40 min of continuous infusion of four different doses of propofol.

Variability is indicated by SE. Bars Labelled with the same letter (a, b, $c$ or d) indicate responses not different from each other. See Methods for details of doses 1-4.

\section{Comparison of the sympathetic responses to pontine} injections of glycine during infusion of different doses of propofol

Sympathetic responses to blockade of the pontine reticular formation by glycine were not different during infusion of doses 1 and 2 (Figure 5). Renal sympathetic activity was depressed by $44 \pm 5 \%$ at dose 1 and by $41 \pm 4 \%$ at dose 2 . During infusion of doses 3 and 4 , 

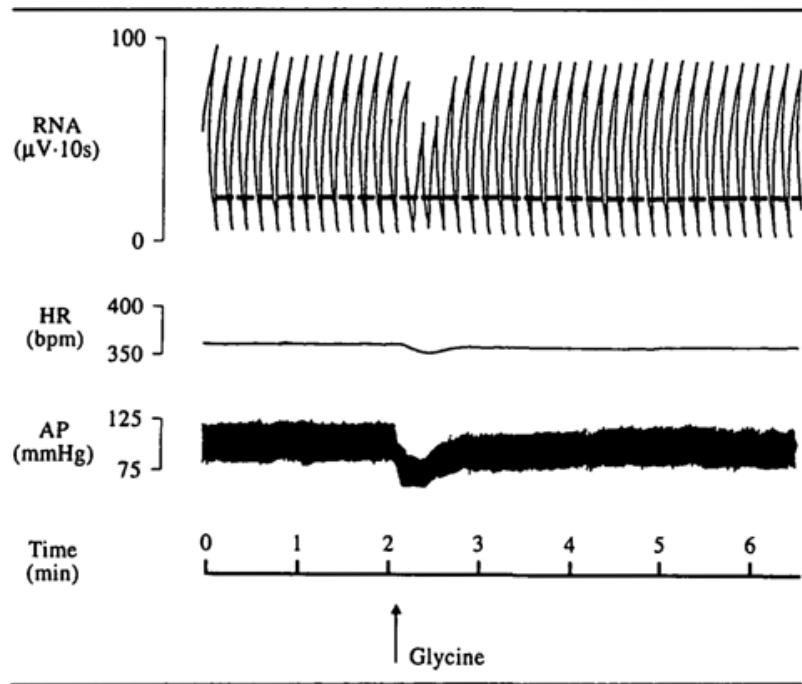

FIGURE 4 Effect of glycine microinjections into the pons on renal nerve activity (RNA), arterial pressure (AP) and heart rate (HR) during propofol anaesthesia $\left(40 \mathrm{mg} \cdot \mathrm{kg}^{-1} \cdot \mathrm{min}^{-1}\right)$. RNA is presented as a polygraph recording of integrated activity; the integrator resets at $10 \mathrm{sec}$ periods. A decrease in renal nerve activity appears as a decrease in the amplitude of each $10 \mathrm{sec}$ wave. The broken line on the RNA represents the level of basal noise during recording. The arrow shows the time of microinjection of the glycine into the pons.

pontine injection of glycine decreased sympathetic activity by $28 \pm 3 \%$ and $13 \pm 2 \%$, respectively. The reduction in response during the highest dose was smaller than that at any of the lower doses. Also changes in mean arterial pressure after pontine microinjections of glycine were smaller as the infused dose of propofol increased (Figure 5). Heart rate changes were less affected by increasing doses of propofol; only the response at dose 4 differed from the response at dose 1 . For comparison, sympathetic and cardiovascular responses to blockade of neurons in the ventrolateral medulla with glycine at doses 1,2 and 4 of propofol from our previous study ${ }^{7}$ are also presented in Figure 5. Dose 4 of propofol depressed arterial pressure, heart rate and sympathetic responses to blockade of pontine neurons significantly more than it depressed responses to blockade of medullary neurons. Similarly, at dose 2 of propofol the change in heart rate induced by blocking pontine neurons was depressed more than that caused by blocking medullary neurons. In contrast, the arterial pressure and sympathetic responses to blockade of pontine neurons by glycine were not different from responses to blockade of medullary neurons during anaesthesia with doses 1 and 2 (Figure 4).

\section{Histological verification of sites of glycine injection into the pontine reticular formation}

The injection sites into the pons are illustrated in Figure 6A. A digitized image of a typical injection site is shown

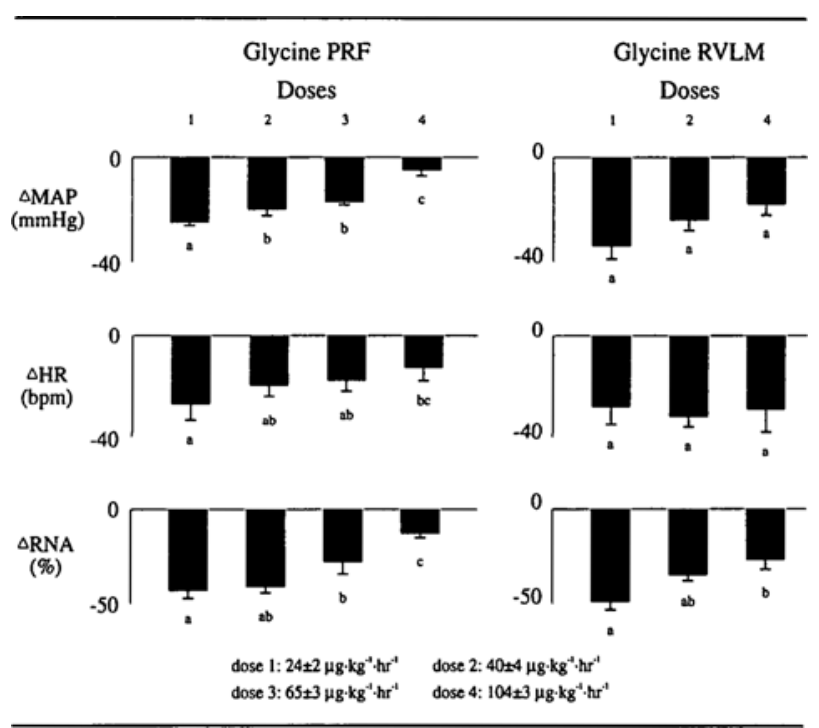

FIGURE 5 Effect of different doses of propofol on responses of RNA, MAP and HR to microinjection of glycine into the pontine reticular formation (PRF; left panel) and rostral part of the ventrolateral medulla (RVLM; right panel). Data pertaining to injections of glycine into the RVLM are taken from our previous study. ${ }^{7}$ Variability is indicated by SE. Bars labelled with the same letter $(a, b$ or $c)$ indicate responses not different from each other. See Methods for list of doses 1-4.

in Figure 6B. Sites in which glycine produced decreases in renal nerve activity, arterial pressure and heart rate (triangles on Figure 6) were found in a pontine region extending caudally from the border of the midbrain to the middle region of the facial nucleus. This region has been described in detail previously. ${ }^{12}$ The rostral pole of the motor nucleus of the trigeminal nerve defined the rostral limit of the region and the caudal limit was the caudal pole of the trapezoid body. The lateral border of this region was approximately at the motor nucleus of the trigeminal nerve, the dorsal border was the dorsal surface of the brainstem and the ventral border was the superior olivary nucleus.

\section{Discussion}

Our results demonstrate that control of sympathetic firing, arterial pressure and heart rate by neurons in the pons was very well maintained during infusion of the lower doses (doses 1 and 2) of propofol which were sufficient to provide light to surgical planes of anaesthesia. However, propofol had moderate to large effects on tonic sympathetic control of the circulation at higher doses.

Previous studies of the central nervous system effects of propofol have focused on changes in the electroencephalogram, cerebral blood flow or local cerebral glucose utilization in different brain structures. ${ }^{2,6,23}$ In contrast to these investigations, we have studied the effects of pro- 


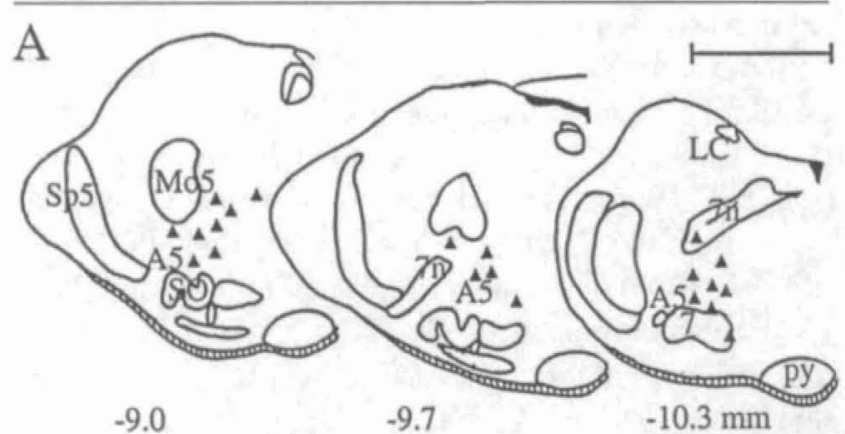

B

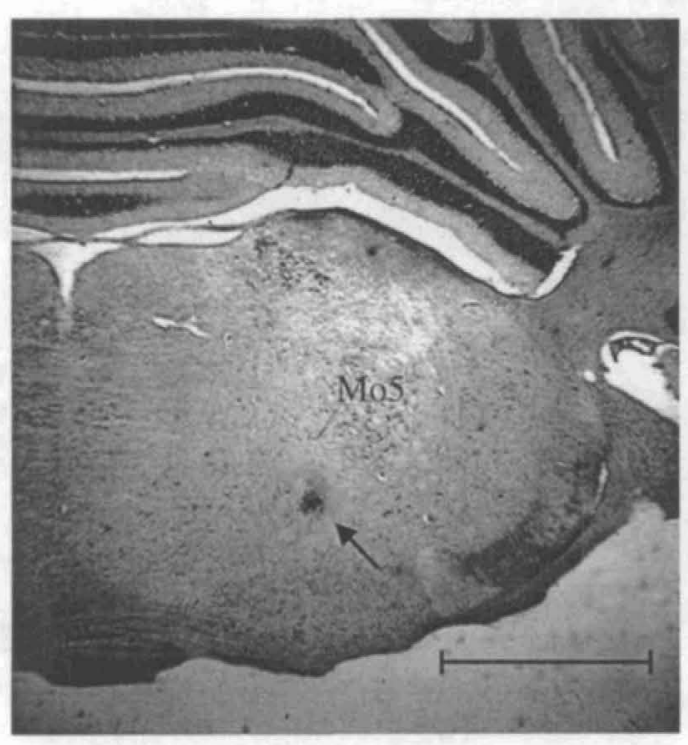

sections of the rat brain (A) and a printed image of a section of the rat brain (B) showing the dye-marked microinjection of into the pons (arrow). The image was produced using a computerized imaging system (Imaging Research, St. Catherines, Canada). A: Triangles respresent injection sites from which responses in renal nerve activity, arterial pressure and heart rate were elicited. Numbers beneath the transverse sections represent the reference level to bregma. For simplicity of illustration, all sites have been plotted on one side of the brain. A5, AS cell group; LC, locus ceruleus; 7n, facial nerve; 7, facial nucleus; SO, superior olivary nuclei; Sps, trigeminal complex; py, pyramidal tract; Mo5, motor trigeminal nucleus. Calibrations for A and $B$ are $2 \mathrm{~mm}$.

pofol on tonically active neurons by using the method of microinjections of the inhibitory amino acid glycine to block the firing of these neurons. Furthermore, unlike previous studies, we have exclusively investigated a brain region involved in the control of cardiovascular and respiratory functions. The experimental design we employed is frequently used to investigate CNS control of the circulation $^{13,14,24}$ and was chosen because changes in arterial pressure, heart rate and sympathetic firing caused by blocking tonically active CNS neurons reveal their role in supporting these functions. Actions of an anaesthetic to blunt cardiovascular reactions to blockade of specific CNS neurons demonstrates that the anaesthetic depresses firing of those neurons. Such depression would restrict their control of the cardiovascular system.

Responses of pontine neurons are of special interest because sympathetic and cardiovascular responses to their blockade by glycine or other inhibitory agents are easily hindered by anaesthetics and the responses were well maintained in our previous studies only in alfaxalonealfadolone anaesthetized rats. ${ }^{12}$ This suggests that tonic control of the circulation by pontine reticular neurons is readily depressed by some anaesthetics. Similarly, neurons in the area postrema of the dorsal medulla that provide input to the neurons in the rostral part of the ventrolateral medulla have recently been shown to be depressed by some anaesthetics such as isoflurane but pressor responses from this area were well preserved during propofol anaesthesia (personal communication: Dr. A. Schubert, Cleveland Clinic Foundation, U.S.A.) In contrast, the substantial cardiovascular and sympathetic depression that is elicited by blocking ventrolateral medullary neurons is similar in rats anaesthetized with several different agents including pentobarbital, alfaxalonealfadolone, propofol and urethane. ${ }^{7,12-14}$ These observations indicate that the ventrolateral medullary vasomotor neurons are more resistant to the actions of anaesthetics than are neurons in other medullary regions or in the higher pontine brainstem region.

One of our objectives was to compare the actions of propofol on two CNS centres known to provide tonic control of the cardiovascular system. Similar overall effects of propofol on sympathetic firing, arterial pressure and heart rate in the current study of pontine control and in the previous study of medullary control ${ }^{7}$ were necessary prerequisites for this comparison. These conditions were almost identical in both studies, allowing our desired comparison to be made. When we investigated the relative depression of pontine and medullary control of the circulation by increasing doses of propofol, one difference was apparent. At the highest dose of propofol, pontine control of sympathetic firing and arterial pressure was blunted considerably more than medullary control. A possible explanation for the greater sensitivity of pontine reticular formation neurons to the highest dose of anaesthetic (dose 4) may relate to a greater sensitivity to anaesthetics of neurons higher in the neuraxis. For example, Dam et al. ${ }^{2}$ evaluated changes in the cerebral metabolic rate for glucose during anaesthesia with propofol and reported greater dose-related decreases in this metabolic rate in the forebrain than in the hindbrain. These selective metabolic changes in forebrain compared to hindbrain neurons have also been observed during alfaxalone-alfadolone and etomidate anaesthesia ${ }^{25,26}$ but 
not during barbiturate anaesthesia. ${ }^{27-29}$ Although no differences in metabolism were noted by Dam et al. between the pons and the medulla, ${ }^{2}$ these investigators did not compare pontine and medullary metabolism at doses of propofol as great as our highest dose. A more profound effect at our highest dose on pontine than medullary metabolism may account for our observation of greater depression of tonic control of circulation by pontine neurons.

The apparently greater sensitivity of pontine than medullary neurons to anaesthetics also may explain why arterial pressure responses to pontine blockade by glycine at the highest dose of propofol were depressed more than those to medullary blockade. The assumption must be made that direct vascular effects of this dose of propofol remain the same whether medullary or pontine neurons are under study. At the deep level of anaesthesia caused by dose 4 , severe depressant actions on the pons summed with the direct vascular effects of propofol whereas, when the actions on medullary neurons were studied, the direct vascular effects of the propofol summed with the lesser depression of medullary neurons yielding smaller changes in arterial pressure.

Explanations of the mechanisms of action of propofol on CNS neurons are incomplete. The known action of propofol to potentiate those of the common CNS inhibitory amino acids such as gamma amino butyric acid (GABA) and glycine ${ }^{30-32}$ may contribute to the depression of pontine and medullary neurons. The effect of propofol on both GABA receptors and glycine receptors on CNS neurons possibly occurs because different CNS receptors have identical binding sites for propofol. ${ }^{32}$ The binding sites may have similar amino acid sequences and, in support of this speculation, GABA and glycine receptors are known to exhibit a high degree of amino acid sequence homology. ${ }^{33}$ Moreover, neurons in both areas are easily inhibited by GABA agonists such as muscimol. ${ }^{12.14} \mathrm{We}$ have previously demonstrated that microinjections of GABA agonists into the pontine reticular formation and the rostral ventrolateral medulla cause reductions in arterial blood pressure, heart rate and sympathetic nerve discharge. ${ }^{12,14}$

In conclusion, at light levels of propofol anaesthesia, the known hypotensive effects probably relate mostly to direct actions on the heart and peripheral vasculature because central sympathetic control of the circulation is not disrupted in a major way. At doses of propofol adequate to provide surgical planes of anaesthesia, depression of the pontine neurons is not severe. As the depth of anaesthesia is further increased, selective effects on CNS vasomotor neurons become more apparent leading to depression of pontine neurons inputs which provide excitatory inputs to the medullary vasomotor centre.

\section{Acknowledgements}

This research was supported by grants from the Heart and Stroke Foundation of Ontario and the Medical Research Council of Canada/Canadian Hypertension Society. L.C. Weaver is a recipient of a Career Investigation Award from the Heart and Stroke Foundation of Ontario and A.V. Krassioukov holds a Fellowship from the Medical Research Council of Canada/Canadian Hypertension Society. The propofol used in this study was kindly donated by Zeneca Pharma, Mississauga, Ontario, Canada. The authors are grateful to Cathy Nutt for assistance with preparation of this manuscript.

\section{References}

1 Aun C, Major E. The cardiovascular effects of ICI 35868 in patients with valvular heart disease. Anaesthesia 1984; 39: 1096-100.

2 Dam M, Ori C, Pizzolato G, et al. The effects of propofol anesthesia on local cerebral glucose utilization in the rat. Anesthesiology 1990; 73: 499-505.

3 Ebert TJ, Muzi M, Berens R, Goff D, Kampine JP. Sympathetic responses to induction of anesthesia in humans with propofol or etomidate. Anesthesiology 1992; 76: 725-33.

4 Grounds RM, Twigley AJ, Carli F, Withwam JG, Morgan $M$. The haemodynamic effects of intravenous induction: comparison of the effects of thiopentone and propofol. Anaesthesia 1985; 40: 735-40.

5 Goodchild CS, Serrao JM. Cardiovascular effects of propofol in the anaesthetized dog. Br J Anaesth 1989; 63: 87-92.

6 Glen JB. Animal studies of the anaesthetic activity of ICI 35 868. Br J Anaesth 1980; 52: 731-41.

7 Krassioukov AV, Gelb AW, Weaver LC. Action of propofol on central sympathetic mechanisms controlling blood pressure. Can J Anaesth 1993; 40: 761-9.

8 Sebel PS, Lowden JD. Propofol: a new intravenous anesthetic. Anesthesiology 1989; 71: 260-77.

9 Sellgren J, Ponten J, Wallin BG. Characteristics of muscle nerve sympathetic activity during general anaesthesia in humans. Acta Anaesthesiol Scand 1992; 36: 336-45.

10 Sellgren J, Ejnell H, Elam M, Pontén J, Wallin G. Sympathetic muscle nerve activity, peripheral blood flows, and baroreceptor reflexes in humans during propofol anesthesia and surgery. Anesthesiology 1994; 80: 534-44.

11 Calaresu $F R$, Yardley $C P$. Medullary basal sympathetic tone. Ann Rev Physiol 1988; 50: 511-24.

12 Hayes $K$, Weaver $L C$. Tonic sympathetic excitation and vasomotor control from pontine reticular neurons. Am J Physiol 1992; 263: H1567-75.

13 Krassioukov $A V$, Weaver $L C$. Connections between the pontine reticular formation and rostral ventrolateral medulla. Am J Physiol 1993; 265: H1386-92.

14 Hayes $K$, Weaver $L C$. Selective control of sympathetic 
pathways to the kidney, spleen and intestine by the ventrolateral medulla in rats. J Physiol 1990; 428: 371-85.

15 Hayes $K$, Calaresu FR, Weaver $L C$. Pontine reticular neurons provide tonic excitation to neurons in rostral ventrolateral medulla in rats. Am J Physiol 1994; 266: R237-44.

16 Feldman $J L$, Ellenberger $H H$. Central coordination of respiratory and cardiovascular control in mammals. Ann Rev Physiol 1988; 50: 593-606.

17 Taylor P. Neuromuscular blocking agents. In: Gilman AG, Goodman LS, Gilman A (Eds.). The Pharmacological Basis of Therapeutics, 6th ed. New York: Macmillan Publishing Co., 1980: 220-34.

18 Beluli DJ. Weaver LC. Differential control of renal and splenic nerves without medullary topography. Am J Physiol 1991; 260: H1072-9.

19 Chevendra V, Weaver LC. Distributions of neuropeptide $Y$, vasoactive intestinal peptide and somatostatin in populations of postganglionic neurons innervating the rat kidney, spleen and intestine. Neuroscience 1992; 50: 727-43.

20 Anonymous. Animal pharmacology. In: Imperial Chemical Industries Technical Manual, Cheshire, England: P.L.C. Alderly Park, 1990: 1-11.

21 Paxinos G, Watson $C$. The Rat Brain in Stereotaxic Coordinates, 8th ed. Orlando: Academic Press, 1986.

22 Snedecor G, Cochran WG. Statistical Methods, 8th ed. Iowa: State University Press, 1989.

23 Van Hemelrijck J, Fitch W, Mattheussen M, Van Aken H, Plets $C$, Lauwers $T$. Effect of propofol on cerebral circulation and autoregulation in the baboon. Anesth Analg 1990; 71: 49-54.

24 Guertzenstein $P G$, Silver $A$. Fall in blood pressure produced from discrete regions of the ventral surface of the medulla by glycine and lesions. J Physiol 1974; 242: 489-503.

25 Davis DW, Hawkins RA, Mans AM, Hibbard LS, Biebuyck $J F$. Regional cerebral glucose utilization during Althesin ${ }^{\circledR}$ anesthesia. Anesthesiology 1984; 61: 362-8.

26 Davis DW, Mans AM, Biebuyck JF, Hawkins RA. Regional brain glucose utilization in rats during etomidate anesthesia. Anesthesiology 1986; 64: 751-7.

27 Sakabe T, Tsutsui T, Maekawa T, Ishikawa T, Takeshita H. Local cerebral glucose utilization during nitrous oxide and pentobarbital anesthesia in rats. Anesthesiology 1985; 63: 262-6.

28 Hodes JE, Soncrant TT, Larson DM, Carlson SG, Rapoport SI. Selective changes in local cerebral glucose utilization induced by phenobarbital in the rat. Anesthesiology 1985; 63: 633-9.

29 Sokoloff $L$, Reivich $M$, Kennedy $C$, et al. The $\left[{ }^{14} \mathrm{C}\right]$ deoxyglucose method for the measurement of local cerebral glucose utilization: theory, procedure, and normal values in the conscious and anesthetized albino rat. $J$ Neurochem 1977; 28: 897-916.
30 Concas A, Santoro G, Mascia MP, Serra M, Sanna E, Biggio $G$. The general anesthetic propofol enhances the function of $\gamma$-aminobutyric acid-coupled chloride channel in the rat cerebral cortex. J Neurochem 1990; 55: 2135-8.

31 Robertson $B$. Action of anaesthetics and avermectin on $\mathrm{GABA}_{\mathrm{A}}$ chloride channels in mammalian dorsal root ganglion neurones. $\mathrm{Br} \mathrm{J}$ Anaesth 1989; 98: 167-76.

32 Hales TG, Lambert JJ. The actions of propofol on inhibitory amino acid receptors of bovine adrenomedullary chromaffin cells and rodent central neurones. Br J Pharmacol 1991; 104: 619-28.

33 Barnard EA, Darlison MG, Seeburg P. Molecular biology of the $\mathrm{GABA}_{\mathrm{A}}$ receptor: the receptor/channel superfamily. Trends Neurosci 1987; 10: 502-9. 